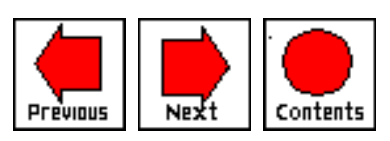

\title{
SPATIAL PLANNING AND REMOTE TEAMWORK
}

\author{
Andreas Voigt and Helena Linzer $\{$ \{bios $\}\}$ \\ with contributions of Robert Vargason \\ Vienna University of Technology \\ Vienna, Austria
}

Editor: Anna Cicognani

\section{ABSTRACT}

The following contribution describes work in progress within the context of the focal field of research and development remote teamwork (RT) of Vienna University of Technology (Dept. of Local Planning - IFÖR), which is carried out in cooperation with the Institute for Spatial Interaction and Simulation (IRISISIS), Vienna, exchanging experience with the Research Institute for Symbolic Computation (RISC Linz-Hagenberg). Research work is aimed at the elaboration of suitable collaborative remote working structures for research and project transactions, including study projects, within the context of spatial planning on the basis of ATM (Asynchronous Transfer Mode: a technology of broad band telecommunications). The generation and manipulation of digital spatial models and their virtual transportation within large spatial distances represent main objectives. The current subjects in urban and regional planning and in architecture act as test projects to be defined in the course of the research project in their contents and spatial context and to be represented as digital spatial working models.

\section{Preface}

Modeling and simulation have become indispensable in the context of spatial planning, and act both on a physio-analogue and virtual-digital level [Linzer et al., 1994]. Spatial planning can be defined as permanent evaluating of spatial development possibilities in the context of changing functional and socioecological objectives. The required spatial impact analysis results in repeated iteration of checking and developing procedures throughout the planning process. In order to advance models in progress, effective planning requires a 
continuous flow of communication, i.e. the transportation of information on planning ideas (e.g. as spatial models) via suitable media mediation.

Teamwork has become a basic requirement for spatial planning. Due to the increase of globalization and cross-linkage of problems, a globally cross-linked teamwork is called for. Therefore teamwork over spatial distance has become an essential field of research.

Remote teamwork (RT) can be defined as the substance related cooperation of people over spatial distances in decision situations. Application of RT is to enhance planning and modeling processes, both in technical and functional terms, thus creating a new planning medium. Teamwork requires repetition and combination of creative and decision stimulating working situations. All the necessary connective and decision stages of a complete planning process have to be assisted.

The present research project is being broadened as an independent field of research to include the applications of spatial planning within the scope of urban and regional planning and architecture. The planning medium to be developed represents an essential contribution for well timed mediation of planning processes and for decision making, taking a globally important issue into account. The described project structure calls for the strategic interaction of institutes and institutions of the entire university, interuniversity cooperation, and the integration of interrelated institutions and cooperation with the economy.

\section{ATM (Asynchronous Transfer Mode)}

The technical functional challenge concerning RT mainly consists of coordinating the actions of all participants in the virtual world and their impact in such a way that all participants receive the view of a singular logical (consistent) world. (Though, in reality, the world is being simulated in portions by various computers.) Apart from several essentially algorithmic problems, the limited band widths of long range computer networks pose the real technological issue [Brutzman et al. 1995].

ATM lends itself extremely well to the realization of RT through high speed networks. ATM was specifically developed as a common platform for the transmission of language, video, and data. It is a broadband telecommunication technology (B-ISDN - Broadband Integrated Services Digital Network) [Cavanaugh-Salo, 1992]).

The RT project requires dealing with specific equipment, both general network infrastructure and specific terminal units. Suitable CAD, simulation, and communication software is useful. 


\subsection{POSSIBLE USES OF ATM}

While ATM can principally transfer every kind of data, we shall deal here with two basically different kinds of utilization:

1. ATM can be used without its quality of service (QOS) parameter, making use only of the high-speed network and transporting any required other record, e.g. IP, with all the advantages and shortcomings of such a record (including transmission overhead).

2. ATM can, however, also be used with its QOS parameter (native ATM), enabling the user or the software to distribute the network load according to specific demands. Differing types of contents (e.g audio, video) are transferred at differing priorities, resulting in differing transmission speeds according to requirements and specific demands. Audio data can have a higher priority level than video data, leading to improved transmission audibility of a lecture during a videoconference, as speech is still transferred with high quality whereas the image might already have faded away.

ATM, featuring the integration of all advantages, including QOS, results in new forms of interaction. Merely using the large bandwidth does not seem sufficiently productive. An efficient implementation accounting for specific requirements and application possibilities of network bandwidths in combination with the QOS parameters will thus prove useful.

\subsection{ADVANTAGES OF ATM}

The major strengths of the ATM technology related to the demands of an advanced spatial planning are briefly described below.

\section{Large Bandwidth}

* Rapid transfer of great quantities of information and data: The high data rate provides for real-time transfer of great data quantities. Example are multimedia applications and interactive cooperation of several partners or partner/teams via the network. Without this high data rate, lively cooperation would not come about, even at small spatial distances.

\section{Demand Driven}

* Adjusting to the requirements and demands of the user, using several channels of communication such as speech, nonverbal communication, gestures and miming, writing and characters, and additional (prepared) presentation material.

Quality of Service (QOS) 
* Setting of differing priorities according to the varying channels of communication, reservation of minimum standards and bandwidths (e.g. audio, video, "data" - model data: 2D, 3D, 4D, qualitative data - textures, colors; topological data; metadata, etc.). QOS ensures the availability of information in a specified quality within a specific time limit.

\section{Standard}

* ATM is standardized (records and equipment).

\section{LAN-Emulation}

* The Lan Emulation Service combines two or more spatially separated local area networks or their components into a logical network, thus lending the impression of a single connected network. By means of this technology the logical separation of two or several groups of users caused by spatial separation of the bunching of network junction points is avoided.

\section{Fields of Application and Communication Periphery}

Advanced spatial planning is not focussed on the technical attractiveness furnished by the ATM technology. Rather, it focusses on the principal specialized fields of application and their impending real benefits for planning work.

\subsection{APPLICATIONS FROM THE PLANNING PERSPECTIVE}

Based on the above mentioned increase in globalizing and networking, new perspectives on planning issues are as follows:

1. Support of "teamwork/collaboration" and any involved working and decision situation, namely, the topics of communication and mediation (computer mediated communication, or CMC); decision supporting in workgroups, e.g. Group Decision Support (GDS); questions related to directing, coordination, and controlling, settlement of conflicts, etc.

2. Support of modeling and simulation, such as establishing and structuring of planning data banks (i.e. design data base, or DDB); interaction with the planning models in real time (distributed virtual reality, or DVR); issues of coherence and consistency of models; etc.

The following roughly structured areas are enumerated as realistic fields of application:

1. Expert support in critical planning and decision situation (equivalent to medical work: preparation of "operations" on the patient city; 
establishment of a "design council" which makes decisions regarding large scale building projects and/or building projects at strategic or prominent spots of a city or a planning space in general);

2. Continuous (i.e. "follow-up") work regarding research and developing projects (e.g. following a conference involving real participation of people).

Special attention is to be rendered in the phases requiring combination, dialogue, and discussion, as well as those for settling disputes and of mediation.

The topics to be elaborated on might develop from the following (incomplete) enumeration of fields of research and development requiring global cooperation:

1. Sustainable utilization of space: spatial impact analysis, including environmental and social compatibility.

2. Forms of building-up and settlements for the third millennium.

3. Low-energy structures.

\subsection{COMMUNICATION PERIPHERY: HARDWARE AND SOFTWARE}

In terms of their general aspects for communication as a basic requirement of teamwork, hardware and software lend themselves to a local and a remote consideration.

Communication Periphery - Hardware

Local:

1. The human being and his "basic equipment" for speaking, moving, acting, gestures, etc.

2. Additional media such as overhead, flipchart, blackboard, poster, slides, video/film, multimedia, physical models etc.

3. (communication) space.

Remote:

1. The human being and his "basic equipment" (see above).

2. Additional media (see above: these media mutate to, for example, the electronic whiteboard or digital images).

3. Virtual space: the media obtain new properties due to data processing and the interaction with models in virtual space.

4. Additional devices

- Userinterface and recording periphery (audio and video, scanner/2D or $3 \mathrm{D}$, digital camera, digitizer) for the participants

- ATM-hardware (cf. below 3.1)

- computer as such 
Remote:

1. data transfer

2. data generation (via CAD, GIS, text editor, etc.)

3. data visualizing and manipulation (rendering, navigation, relocation, morphing, etc.)

\section{Technical Situation at the Vienna University of Technology}

The research project "Remote Teamwork" is being carried out by the Dept. of Local Planning (Vienna University of Technology) with very active support of the Center of EDP (ZID Vienna Center of Technology) in cooperation with the Institute for Spatial Interaction and Simulation (IRIS-ISIS Vienna).

Furthermore, there is an exchange of experience with the Research Institute for Symbolic Computation (RISC Hagenberg) of the Kepler University Linz.

At the time of this writing the "Remote Teamwork" project has the following characteristics:

\subsection{ATM HARDWARE}

The present configuration is made up of:

- Real-world Interfaces At present 2 SiliconGraphics Indy Workstations with R5000 processors and 96 MB memory and a SiliconGraphics O2 with 128 MB memory / SiliconGraphics Reality Engine2 Onyx. The Indy\&O2 Workstations are equipped with Indycam and an A2 Audio Processor.

- ATM Interfaces The connection at the ATM-side is granted by three GIA-200 Fore Runner ATM by FORE each equipped with a 25mHZ i960 offering a transfer rate of155 Mbit/sec.

- ATM-Switch The ATM-switch at the Vienna University of Technology (LS 2020, 1010, resp.) having been donated by Ericsson-Schrack Austria for the project "CIVIC) connects the machines as well as any possible project partners (e.g. Johannes Kepler University Linz, Ars Electronica Center Linz, Graz University of Technology and any such international partners within or beyond the European Union).

- General Network Infrastructure

\subsection{IMPLEMENTATION}

Every new medium and every new technology is to be "cultivated" in line with the user's needs and the specific requirements and the individual components to be combined effectively. 
The characteristic qualities of forms and media of communication are to be regarded in view of the new possibilities offered, priorities in the fields of "channels and periphery of communication" are to be set, new applications are to be developed utilizing the characteristics and strong points of the new technology efficiently. Simple digital reproduction of analogue or local techniques is not deemed to be sufficient. The most important preliminary issues to be tackled are:

1. classification and selection of data (audio, video, model data, etc.)

2. data properties and characteristics (e.g.: requirement of constant transfer rate for audio, minimum resolution and contrast of image data, etc.)

3. requirements concerning transfer and reception of data and information

4. "instructions": the new technology will call for the development and adaption of instructions for communicating, a new discipline of communication will result.

\subsection{TEST SET}

A possible test set for the new technology comprises such fields as:

1. testing the ATM-standards (IP over ATM, native ATM)

2. testing the existing software to the extent it lends itself as part components of the planning application "Remote Teamwork"

3. based on above tests and experience: development of new applications making due use of the standards in line with the design requirements.

4. Review and Outlook

The research project "Remote teamwork" is "work in progress". Essential partial experience has been gained in the course of parts of the projects completed.

Table: Test Set ATM - Vienna University of Technology (E268/01/1997)

\begin{tabular}{|c|l|l|l|}
\hline $\begin{array}{c}\text { Technical } \\
\text { possibilities }\end{array}$ & $\begin{array}{l}\text { Test to be } \\
\text { performed }\end{array}$ & Design Relevancy & Remarks \\
\hline $\begin{array}{c}\text { number of } \\
\text { participants }\end{array}$ & $\begin{array}{l}\text { within Vienna University } \\
\text { of Technology } \\
\text { Austria-wide } \\
\text { EU-wide and worldwide }\end{array}$ & presentation & $\begin{array}{l}\text { establishing virtual } \\
\text { LANs }\end{array}$ \\
\hline
\end{tabular}




\begin{tabular}{|c|c|c|c|}
\hline $\begin{array}{l}\text { - large } \\
\text { bandwidth }\end{array}$ & videoconferencing (VIC) & presentation & e.g. IP over ATM \\
\hline & file transfer & presentation & $\begin{array}{l}\text { e.g. urban spatial } \\
\text { models, architectural } \\
\text { models }\end{array}$ \\
\hline & $\begin{array}{l}\text { (local) interaction with } \\
\text { the data model }\end{array}$ & $\begin{array}{l}\text { presentation, development } \\
\text { of variants, spatial impact } \\
\text { analysis }\end{array}$ & $\begin{array}{l}\text { e.g navigation, } \\
\text { relocation, morphing }\end{array}$ \\
\hline $\begin{array}{l}\text { - } \text { quality of } \\
\text { service } \\
\text { (QOS) }\end{array}$ & $\begin{array}{l}\text { combination of } \\
\text { "channels of } \\
\text { communication" }\end{array}$ & $\begin{array}{l}\text { presentation, dialogue and } \\
\text { interaction }\end{array}$ & $\begin{array}{l}\text { native ATM } \\
\text { various applications } \\
\text { required }\end{array}$ \\
\hline $\begin{array}{l}\text { - combination } \\
\text { of large band } \\
\text { width and } \\
\text { QOS }\end{array}$ & $\begin{array}{l}\text { (cf. tests large } \\
\text { bandwidth) }\end{array}$ & $\begin{array}{l}\text { presentation and } \\
\text { development of variants } \\
\text { (distributed modeling), } \\
\text { spatial impact analysis }\end{array}$ & $\begin{array}{l}\text { computerintegrated } \\
\text { videoconferencing } \\
\text { (CIVIC) } \\
\text { various applications } \\
\text { required }\end{array}$ \\
\hline $\begin{array}{l}\text { - combination } \\
\text { of large } \\
\text { bandwidth, } \\
\text { QOS and } \\
\text { planning } \\
\text { aspects }\end{array}$ & $\begin{array}{l}\text { integration of the re } \\
\text { quirements of planning - } \\
\text { various tests in the field } \\
\text { distributed virtual reality } \\
\text { (DVR) }\end{array}$ & $\begin{array}{l}\text { interaction, development of } \\
\text { variants and spatial impact } \\
\text { analysis (shared modeling) }\end{array}$ & $\begin{array}{l}\text { computerintegrated } \\
\text { spatial planning } \\
\text { (CISP), development } \\
\text { and integration of } \\
\text { software }\end{array}$ \\
\hline
\end{tabular}

\subsection{FIELDS OF EXPERIENCE}

The following illustrate related projects (detailed information to be gathered from the sources indicated). Special attention has been given to the field of planning and design work related to building planning: "Bebauungs-planung", or building regulation, as well as configurating the city volume (\#1, 2, 3, and 4) and joint design study projects $(\# 3,5)$.

1. Special Internet Videoconferences (VIC) - eg. Vienna-Linz (1994)

2. New Aspects Regarding Building-up Planning (1994- 96)

3. Workshop Vienna-Aspern (EAEA 1995) - A complex urban-design concept; distributed modeling \& multimedia [Martens et al., 1995]

4. ComputerIntegrated City Development (CIVIC, TU Wien 1995/96 [Martens et al., 1995])

5. Bragraluwi - A Joint Design Studies Project - Development of collaborative CAD-based design solutions for the reuse of four large brick built 
gasometers located in Vienna [Martens et al., 1996b]

6. VRML-Workshop: A Team is Looking into VRML Martens et al., 1996b]

7. Test series ATM (1996/97/98)

In conclusion, essential questions regarding collaborative RT are enumerated in Figure 2 accordingly to substance-related, organizational, and technical aspects [Martens et al. 1996b, modified]. The experiences can be compared with a soccer game representing something like a CT (observation of rules of game, strategy of coaches, passing, self- responsibility when having in the ball, etc.).

\begin{tabular}{|c|c|}
\hline Substance-related Aspects & \\
\hline -Which qualities are to expected? & $\begin{array}{l}\text { Research: substance-related matters (eg. } \\
\text { concerning spatial planning) vs. further } \\
\text { development of working tools for } \\
\text { collaboration/teamwork } \\
\text { Teaching: promotion of sophisticated working } \\
\text { methods; capability for project management; } \\
\text { thinking in concepts and variants; activaition of } \\
\text { criticism and possibilities for discussion; } \\
\text { strenghtening of responsibility }\end{array}$ \\
\hline - Which risks may be involved latently? & $\begin{array}{l}\text { Domination of technical fascination; repressing of } \\
\text { substance-related matters; no conclusive results }\end{array}$ \\
\hline $\begin{array}{l}\text { Which topics lend themselves to RT and } \\
\text { which of them well? }\end{array}$ & $\begin{array}{l}\text { The range comprises conceptive urban structural } \\
\text { considerations, the planning of the complete } \\
\text { structure right to the design of specific objects. } \\
\text { Certain topics and working stages are, however, } \\
\text { extremely well suited for RT }\end{array}$ \\
\hline \multicolumn{2}{|l|}{ Organizational Aspects } \\
\hline - Which position should RT receive? & $\begin{array}{l}\text { Research: position within research context } \\
\text { Teaching: position in the curricula, rating and kind } \\
\text { of lecture class }\end{array}$ \\
\hline $\begin{array}{l}\text { - How should the information- and } \\
\text { communication flow be configurated? }\end{array}$ & $\begin{array}{l}\text { Choice, dimensioning and presentation of } \\
\text { information; degree of abstraction; pace of } \\
\text { handling }\end{array}$ \\
\hline - How is competence structured and limited? & $\begin{array}{l}\text { Hierarchic structures; supervising; equal status of } \\
\text { decision-makers; laissez-faire; vertical } \\
\text { (top-down/bottom-up) versus horizontal processes }\end{array}$ \\
\hline Technical Aspects & \\
\hline
\end{tabular}




\begin{tabular}{|l|l|}
\hline $\begin{array}{l}\text { - Which techniques are suited in support of } \\
\text { information flow? }\end{array}$ & $\begin{array}{l}\text { Internet (www including e-mail, ftp, talk), HTML, } \\
\text { VRML, video-conferencing with whiteboard- and } \\
\text { AV-tools }\end{array}$ \\
\hline - Which technical limitations exist? & $\begin{array}{l}\text { Transmission band widths; communication } \\
\text { periphery; net connection; general accessibility }\end{array}$ \\
\hline
\end{tabular}

\subsection{AGENDA}

The complexity of the defined field of research and development calls for the concentrated, strategical, and efficient cooperation of university research institutions, producers of hardware and software, and user groups in planning and planning administration. The following is required:

- availability of a meaningful range of software applications, i.e. contact and exchange of experience with - holders of applications and - developers of applications

- performance of definite tests with partners - optimizing of exchange of experience - determination of avoidable problems

- setting of possible goals for future development - applications for planners - applications for decision-makers

- Know-how regarding extent of utilization, feasibility of solutions developed

\section{REFERENCES}

- BRUTZMAN, Donald P., MACEDONIA, Michael R. and ZYDA, Michael J. (1995): "Internetwork Infrastructure Requirements for Virtual Environments" NII 2000 Forum of the Computer Science and Telecommunications Board, National Research Council, Washington, D.C., May 1995

- CAVANAUGH, John D., SALO, Timothy J. (1992): "Internetworking with ATM WANs" Minnesota Supercomputer Center, Inc.

- LINZER, Helena, MARTENS, Bob, VOIGT, Andreas (1994): "The Integration of Virtual and Full Scale Modelling" in MAVER, Tom, PETRIC; Jelena (Ed.): The Virtual Studio. ECAADE-Proceedings. Glasgow

- MARTENS, Bob, VOIGT, Andreas, SCHMIDINGER, Elmar, LINZER, Helena (1995): "The Effective Use of Multimedia and Telematics" in COLAJANI, Benedetto,

- PELLITTERI, Giuseppe (Ed.): Multimedia and Architecural Disciplines. ECAADE-Proceedings. ISBN 095236871 4. Palermo 1995

- MARTENS, Bob, VOIGT, Andreas, SCHMIDINGER, Elmar, LINZER, Helena (1996a): "Information Technologies within Academic Context" in KVAN, Thomas (Ed.): The Introduction of Technology, CAADRIA-Proceedings. ISBN 9627-75-703-9. Hongkong 1996 
- MARTENS, Bob, DOKONAL, Wolfgang, SCHMIDINGER, Elmar, VOIGT, Andreas (1996b): "Collaborative Teamwork - Challenges of the Future" ECAADE-Proceedings. Lund 1996

\section{BIOGRAPHIES}

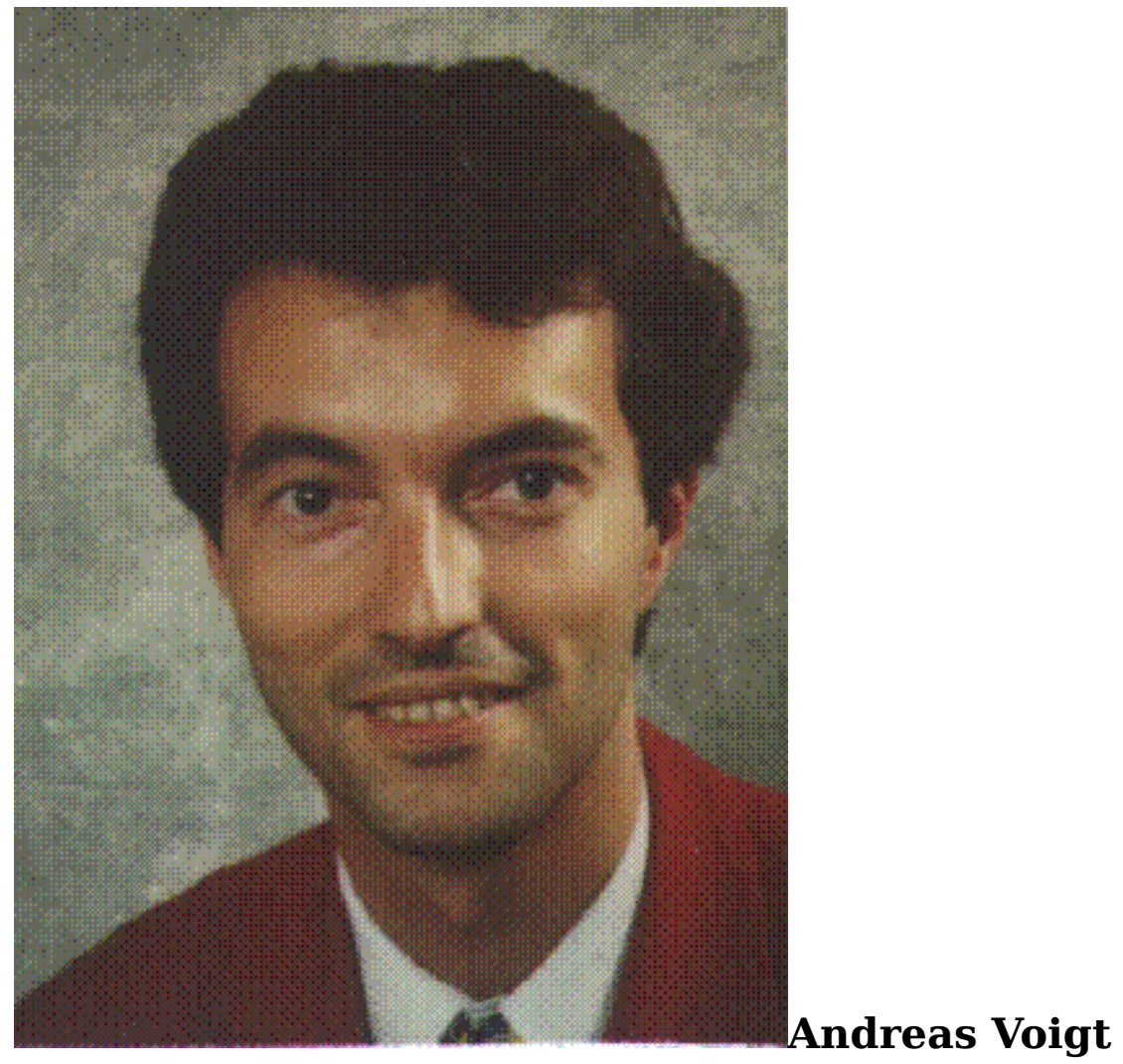

Andreas Voigt, Dipl.-Ing. Dr. techn., was born on Oct. 8, 1962 in Linz, Upper Austria. During 1981-86 he studied urban and regional planning at the Vienna University of Technology. Since 1986 he has been associated with the Institute for Local Planning at the Vienna University of Technology, mainly teaching and doing research in various fields such as simulation assisted spatial planning, building planning, and spatial information systems. In 1994 he passed the civil engineer exam for the field of urban and regional planning. In 1993 he co-founded the "ArGe Projekte" (Joint Venture Projects), and in 1994 he co-founded the Institute for Spatial Interaction and Simulation (ISIS). 


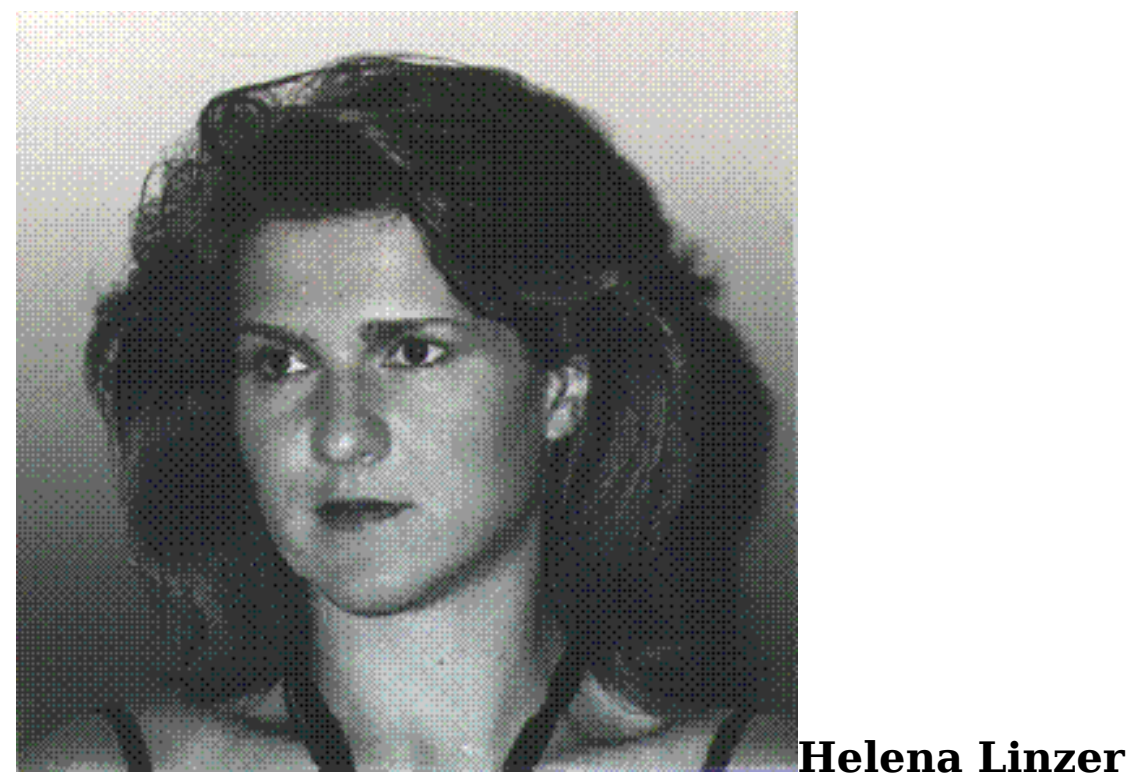

Helena Linzer, Dipl.-Ing., was born May 26, 1959, in Oberpullendorf, Burgenland, Austria. During 1977-83 she studied urban and regional planning at the Vienna University of Technology. Since 1981 she has been engaged in freelance activities with private engineers, research institutes, and university institutes - mainly in the fields of urban and regional planning, and energy and environmental issues. Since 1986 she has been an associate at the Institute for Local Planning at the Vienna University of Technology. There she is in charge of local development planning and master planning, and village renewal and development. In 1990 she passed the civil engineer exam for the field of urban and regional planning; in 1993 she co-founded the "ArGe" (Joint Venture Projects), and in 1994 she co-founded the Institute for Spatial Interaction and Simulation (ISIS).

Contact information for all three contributors:

Vienna University of Technology (TU Wien)

Faculty of Urban and Regional Planning \& Architecture

Dept. for Local Planning (IFOER)

Karlsgasse 11/5, A-1040 Wien, Austria

Email:

- voigt@ifoer.tuwien.ac.at

- linzer@ifoer.tuwien.ac.at

- robert@ifoer.tuwien.ac.at

Phone: $++43 / 1 / 58801$ ext 4275 or 4273

FAX: $++43 / 1 / 5044187$

URL: www.ifoer.tuwien.ac.at> 


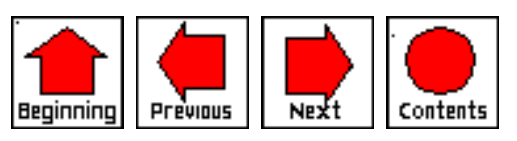

